\title{
Microvascular abnormalities in capillaroscopy correlate with higher serum IL-18 and sE-selectin levels in patients with type 1 diabetes complicated by microangiopathy
}

\author{
Anna Kuryliszyn-Moskal ${ }^{1}$, Artur Dubicki ${ }^{2}$, Wiesław Zarzycki ${ }^{3}$, Anna Zonnenberg ${ }^{4}$, \\ Maria Górska ${ }^{3}$
}

\author{
${ }^{1}$ Department of Rehabilitation, Medical University of Bialystok, Poland \\ ${ }^{2}$ Department of Invasive Cardiology, Medical University of Bialystok, Poland \\ ${ }^{3}$ Department of Endocrinology, Diabetology and Internal Diseases, Medical University \\ of Bialystok, Poland \\ ${ }^{4}$ College of Computer Science and Business Administration in Lomza Medical Institute, Poland
}

\begin{abstract}
Microvascular abnormalities are one of the most important causes of persistent diabetic complications. The aim of this study was to compare microvascular changes examined by nailfold capillaroscopy with serum concentrations of soluble E-selectin (sE-selectin) and IL-18 in type 1 diabetic patients with and without microangiopathy. Serum levels of sE-selectin and IL-18 were determined by an enzyme-linked immunosorbent assay in 106 patients with type 1 diabetes and in 40 healthy controls. All diabetic patients were evaluated by extensive clinical, laboratory and capillaroscopic studies. Morphological changes were observed by nailfold capillaroscopy in 86 out of 106 (81\%) diabetic patients. Severe capillaroscopic changes were seen in 32 out of $54(59 \%)$ patients with microangiopathy, but in only seven out of $52(13 \%)$ patients without microangiopathy. Higher serum levels of sE-selectin $(\mathrm{p}<0.001)$ and IL-18 ( $<<0.05)$ were demonstrated in diabetic patients compared to controls. Significant differences of sE-selectin $(\mathrm{p}<0.001)$ and IL-18 $(\mathrm{p}<0.01)$ serum concentrations were observed between diabetic patients with microangiopathy and controls. Moreover, comparison between patients with and without microangiopathic complications showed a significantly higher capillaroscopic score and sE-selectin serum concentration in the group with microangiopathy $(p<0.001)$. Furthermore, diabetic patients with severe microvascular changes in capillaroscopy showed significantly higher IL-18 ( $\mathrm{p}<0.001)$ and sE-selectin $(\mathrm{p}<0.05)$ serum levels than subgroups without changes or with mild abnormalities. Our findings suggest that abnormalities in nailfold capillaroscopy may reflect the extent of microvascular involvement and are associated with higher sE-selectin and IL-18 serum levels, as well as with microangiopathic complications in diabetic patients. (Folia Histochemica et Cytobiologica 2011; Vol. 49, No. 1, pp. 104-110)
\end{abstract}

Key words: capillaroscopy, IL-18, soluble E-selectin, type 1 diabetes, microangiopathy

\section{Introduction}

Microvascular abnormalities are one of the most important causes of persistent diabetic complications.

Correspondence address: A. Kuryliszyn-Moskal,

Department of Rehabilitation, Medical University of Bialystok, M. Curie-Sklodowska Str. 24a, 15-276 Bialystok, Poland;

tel./fax: (+ 48 85) 74683 15;

e-mail: akuryl@umb.edu.pl
Endothelial dysfunction plays a key role in the development of vascular disease and represents an early stage in the pathogenesis of diabetic microangiopathy [1].

Damaged or activated endothelial cells are a target and the source of various factors responsible for the control of vascular tone, coagulation systems and inflammatory processes, among which endothelial selectin (E-selectin) has attracted attention as a speci- 
fic marker of endothelial activation and as an angiogenic mediator [2]. Stimulation of endothelial cells leads to release of the soluble form of E-selectin (sE-selectin), and its serum concentration might be related to endothelial cell damage [3]. Increased serum levels of sE-selectin have been reported in several connective tissue diseases [4], coronary heart disease [5] and systemic inflammatory response syndrome [6]. Moreover, it has been suggested that sE-selectin plays an important role in the pathogenesis of microvasculature disorders in diabetes [7]. A previous study demonstrated a relationship between sE-selectin serum concentration and microvascular abnormalities in nailfold capillaroscopy in patients with systemic lupus erythematosus (SLE) [8].

Recently, it has been recognized that the inflammatory process accompanying increased concentration of proinflammatory cytokines and plasma adhesion molecules plays an important role in the pathogenesis of diabetes [3].

Interleukin 18 is a proinflammatory cytokine which exerts a number of biological activities [9]. In pathological conditions, IL-18 is involved in angiogenesis [10], arteriosclerosis [11], tissue destruction, and seems to play a role in the autoimmune $\beta$-cell destruction [12]. Recent studies have shown that circulating IL-18 may be a predictor of progression of diabetic nephropathy as well as cardiovascular diseases [13].

Nailfold capillaroscopy (NC) has been used as a non-invasive and sensitive technique for evaluating microvascular involvement, mainly in connective tissue diseases, including scleroderma-spectrum disorders [14], systemic lupus erythematosus [8], juvenile idiopathic arthritis [15] and other connective tissue diseases [16].

Morphological and functional changes in capillary microscopy have been reported in diabetic patients, mainly in relation to vascular reactivity after induced ischemia [17]. In our previous study, we evaluated the relationship between microvascular abnormalities in capillaroscopy and diabetic microangiopathy in patients with type 1 diabetes mellitus [18]. There has also been found to be a relationship between the severity of microvasculature changes and metabolic control of diabetes [19].

Despite all these findings, little data exists on the relationship between microvascular changes in capillaroscopy, disease feature, and endothelial cell activation markers. Therefore, the aim of this study was to compare microvascular abnormalities examined by nailfold capillaroscopy with serum concentrations of sE-selectin and IL-18 in type 1 diabetic patients with and without microangiopathy.

\section{Material and methods}

\section{Patients}

The study included 106 patients with type 1 diabetes, treated in the Clinical Department of Endocrinology, Diabetology and Internal Diseases and Diabetic Polyclinic of Clinical Hospital of Medical University in Bialystok. The study was approved by the Ethics Committee of the Medical University of Bialystok (resolution No. R-I-002/96/2008), and informed consent was obtained from each patient.

All patients were evaluated by clinical, laboratory and capillaroscopic studies on the day of blood sample collection. The weight and height of all patients was recorded, their BMI calculated and biochemical parameters, such as $\mathrm{HbA}_{1 \mathrm{c}}$ (HPLC Variant, BIO-RAD Laboratories, Germany), total cholesterol, HDL-cholesterol, triglycerides (TG) (enzyme assay, ANALCO-GBG, Poland) and LDL-cholesterol (calculated from Friedewald formula), were measured.

Based on the medical records, the prevalence and progress of chronic complications were determined. According to clinical and laboratory examinations, the whole group of diabetic patients was subdivided into patients without (Group A, $\mathrm{n}=52$ ) and with microangiopathy (Group $B, n=54$ ) i.e. retinopathy (45 patients), nephropathy (29 patients) and/or neuropathy (41 patients). All diabetic patients were on insulin therapy comprising at least three insulin doses per day. Exclusion criteria from our study were: vascular coexistent disorders, hypertension, hepatopathy, smoking, active infection, vascular effective drug use and hand lesions.

The control group consisted of 40 healthy volunteers comparable in terms of age, sex, and body mass index. Table 1 shows the characteristics of the type 1 diabetic patient group and the control group.

\section{Clinical and laboratory analysis}

Ophtalmological and neurological examinations, renal ultrasonography, renal function tests, peripheral blood cell counts, hemoglobin concentration, serum creatinine, creatinine clearance, urinalysis, albuminuria, daily urinary protein excretion and erythrocyte sedimentation rate (ESR) were performed for all patients.

\section{Serum specimen preparation}

For the determination of serum analyses, venous blood samples were collected, after overnight fasting, 
in tubes without additives. Serum was prepared from blood samples by centrifugation at 3,000 $\mathrm{g}$ for $10 \mathrm{minu}-$ tes and then immediately transferred in aliquots into plastic tubes and stored at $-80^{\circ} \mathrm{C}$.

\section{Laboratory studies}

The serum levels of sE-selectin and interleukin 18 concentrations were analyzed by ELISA kits (Parameter Human sE-Selectin Immunoassay, R\&D Systems and Medical \& Biological Laboratories, Freiburg, Germany). The experimental procedures were performed adhering strictly to the manufacturer's instructions.

\section{Nailfold capillaroscopy}

All patients underwent a nailfold capillaroscopy examination using a stereomicroscope SZ 4045 with a final magnification of $\times 200$ (Olympus, Germany). A fiber-optic light source and filter provided cold illumination. The optical microscope was connected to a color digital camera and a personal computer. The images taken at the time of examination were analyzed by the same experienced investigator (AKM). Each patient was allowed to acclimatize for 20 minutes at a room temperature of $20-24^{\circ} \mathrm{C}$ before the examination.

The nailfold of all fingers (not the thumbs) were examined in 10-100 zoom after a drop of immersion oil was placed on the nailfold bed. The mean score for each patient was obtained from the analysis of all studied fingers. The loop density in $1 \mathrm{~mm}$, numbers and morphology of loops with architectural derangement, and the presence of extravasations were evaluated. The intensity of morphological changes was expressed according to the accepted classification $[8,17]$ and ranged from 0 to 3 : a score of 0 indicated no changes $(<13$ capillaries/ $/ \mathrm{mm}$, hairpin-shaped loops arranged in parallel rows, absence of hemorrhages); a score of $1=$ mild $(<13$ capillaries $/ \mathrm{mm},<20 \%$ capillaries longer than $750 \mu \mathrm{m},<50 \%$ morphologically changed capillaries, arranged in parallel rows, absence of hemorrhages); a score of $2=$ moderate $(<9$ capillaries/ $/ \mathrm{mm}$, more than $20 \%$ capillaries longer than $750 \mu \mathrm{m}$, $50-75 \%$ changed loops with irregular distribution of the capillary array, increased visibility of subpapillary venular plexus, without extravasations): and a score of $3=$ severe changes $(<9$ capillaries/ $/ \mathrm{mm}$, capillary length variability, more than $75 \%$ changed loops such as meandering, ramified and/ /or disarranged capillaries with the presence of hemorrhages).

\section{Statistical analysis}

Statistical analysis of the results was carried out using Statistica 8.0 software from StatSoft. Data was analyzed by the Mann-Whitney U-test. The probability of differences in frequency distributions was determined by chi-square test or Fisher's exact test. In all calculations, $\mathrm{p}<0.05$ were considered statistically significant.

\section{Results}

There were no significant differences in age, gender, body mass, growth or BMI between the group of patients with type 1 diabetes and the healthy controls. Biochemical parameters such as $\mathrm{HbA}_{1 \mathrm{c}}$ concentration, total cholesterol, triglycerides, LDL-cholesterol and creatinine were significantly higher, and HDL-cholesterol level was significantly lower, in diabetic patients compared to the control group (Table 1).

The NC patterns of 106 patients with type 1 diabetes and 40 healthy controls were examined in this study. The capillaroscopic feature of the control group showed hairpin capillaries in a parallel arrangement. All healthy controls reached a capillaroscopic score $=0$.

Patients with type 1 diabetes had spiral loops with decreased density and dilatation of the apical part and the venous limb. Normal capillaroscopic patterns (score 0 ) were observed in $20(19 \%)$, minor abnormalities (score 1) in $29(27 \%)$, moderate in $18(17 \%)$ and severe in the remaining 39 of the 106 (37\%) diabetic patients. The duration of disease was longer in diabetic patients with severe capillaroscopic changes $(20.3 \pm 10.2$ years $)$ than in patients with mild (12.63 \pm 10.9 years $)$ or moderate $(15.7 \pm 10.8$ years $)$ microvascular abnormalities.

A comparison between the type 1 diabetic patients with (Group B) and those without microangiopathy (Group A), found there to be a significantly higher capillaroscopic score in patients with $(2.3 \pm$ $\pm 1.0)$ than without microangiopathy $(1.15 \pm 1.0$; $\mathrm{p}<0.001)$. Severe morphological changes in nailfold capillaroscopy were observed in 32 out of 54 (59\%) patients with microangiopathy but only in seven out of $52(13 \%)$ diabetic patients without microangiopathy. Moreover, normal capillaroscopic patterns or minor abnormalities (score $0-1$ ) were found in 15 (28\%) patients from Group B compared to 34 (66\%) patients from Group A.

Serum levels of sE-selectin and IL-18 were determined in 106 type 1 diabetic patients, 52 of them without microangiopathy and 54 with microangiopathic 
Table 1. Clinical characteristic of diabetic patients and controls

\begin{tabular}{|c|c|c|c|}
\hline Characteristics & $\begin{array}{c}\text { Patients } \\
\text { (mean } \pm \text { SD) } \\
n=106\end{array}$ & $\mathbf{p}<$ & $\begin{array}{c}\text { Control group } \\
\text { (mean } \pm \text { SD) } \\
n=40\end{array}$ \\
\hline Age (years) & $37.60 \pm 12.83$ & NS & $33.25 \pm 10.06$ \\
\hline Disease duration (years) & $14.61 \pm 10.9$ & - & - \\
\hline $\mathrm{BMI}\left[\mathrm{kg} / \mathrm{m}^{2}\right]$ & $23.93 \pm 4.05$ & NS & $22.87 \pm 3.5$ \\
\hline $\mathrm{HbA}_{1 \mathrm{c}}(\%)$ & $8.29 \pm 2,27$ & 0.001 & $4.53 \pm 0.4$ \\
\hline Total cholesterol [mg/dl] & $191.19 \pm 48.0$ & 0.01 & $166.70 \pm 22.6$ \\
\hline Triglycerides [mg/dl] & $117.66 \pm 95.8$ & 0.01 & $73.98 \pm 33.4$ \\
\hline HDL-cholesterol [mg/dl] & $52.46 \pm 14.8$ & 0.01 & $60.35 \pm 17.6$ \\
\hline LDL-cholesterol [mg/dl] & $115.19 \pm 39.4$ & 0.001 & $91.56 \pm 25.5$ \\
\hline Serum creatinine $[\mathrm{mg} / \mathrm{dl}]$ & $0.91 \pm 0.30$ & 0.001 & $0.73 \pm 0.1$ \\
\hline Retinopathy (no. of patients) & 45 & - & - \\
\hline Nephropathy (no. of patients) & 29 & - & - \\
\hline Neuropathy (no. of patients) & 41 & - & - \\
\hline
\end{tabular}

NS — non significant

Table 2. Serum concentrations of soluble E-selectin (sE-selectin) $[\mathrm{ng} / \mathrm{ml}]$ and IL-18 [pg/ml] in patients with type 1 diabetes according to the presence of microangiopathy and in healthy controls. Data is shown as mean \pm SD

\begin{tabular}{|l|c|c|c|c|}
\hline Parameters & \multicolumn{2}{|c|}{ Diabetic patients } & Together & Controls \\
\hline & Without microangiopathy $(\mathbf{n}=\mathbf{5 2})$ & With microangiopathy $(\mathbf{n}=\mathbf{5 4})$ & $(\mathbf{n}=\mathbf{1 0 6})$ & $(\mathbf{n}=\mathbf{4 0})$ \\
\hline sE-selectin & $56.86 \pm 17.84^{3}$ & $80.77 \pm 51.99^{1,4}$ & $69.04 \pm 40.78^{1}$ & $32.81 \pm 10.14$ \\
\hline IL-18 & $248.57 \pm 84.40$ & $267.99 \pm 100.68^{2}$ & $258.47 \pm 93.12^{3}$ & $217.41 \pm 59.81$ \\
\hline
\end{tabular}

${ }^{1}$ Statistical significance: $\mathrm{p}<0.001$ compared to healthy controls; ${ }^{2}$ Statistical significance: $\mathrm{p}<0.01$ compared to healthy controls;

${ }^{3}$ Statistical significance: $\mathrm{p}<0.05$ compared to healthy controls; ${ }^{4}$ Statistical significance: $\mathrm{p}<0.05$ between both diabetic groups

complications, and in 40 healthy subjects. Higher serum concentrations of sE-selectin $(p<0.001)$ and IL-18 ( $p<0.05)$ were observed in diabetic patients compared to the control group. Moreover, significant differences of sE-selectin ( $p<0.001)$ and IL-18 ( $p<$ $<0.01$ ) serum concentrations were observed between diabetic patients with microangiopathy and controls. Although patients with microangiopathy demonstrated higher serum levels of IL-18 and sE-selectin than patients without microangiopathy, significant differences were only found in sE-selectin concentrations $(\mathrm{p}<0.05)$ (Table 2).

To demonstrate the relationships between capillaroscopic abnormalities, sE-selectin and IL-18 serum levels, the four subgroups of diabetic patients were distinguished according to the severity of capillaroscopic changes. Patients with severe capillaroscopic abnormalities showed significantly higher sE-selectin and IL-18 serum levels than patients with normal capillaroscopic pattern or with mild changes $(\mathrm{p}<0.05$; $\mathrm{p}<0.001$, respectively) (Tables 3,4 ).

\section{Discussion}

Although progress in diagnostic and treatment procedures has dramatically improved the quality of life for young diabetic patients, the mortality rate in this group is still significantly higher than in the general population, mostly due to the development of microand macroangiopathic complications. It is claimed that endothelial cell activation and damage play a potentially crucial role in the pathogenesis of microvascular complications in diabetes $[1,10]$. Hence, the early diagnosis of vascular pathology is vital for the therapy of diabetic patients. Therefore, growing evidence points to the need for reliable methods of visualizing the morphological changes in microcirculation.

Nailfold capillary microscopy has been used extensively as a non-invasive means of investigating microvascular involvement. Our previous studies reported the diagnostic value of nailfold capillary abnormalities and their correlation with organ systemic 
Table 3. Serum concentrations of soluble E-selectin (sE-selectin) in patients with type 1 diabetes according to the severity of microvascular changes in capillaroscopy and in healthy controls

\begin{tabular}{|l|c|c|c|}
\hline $\begin{array}{l}\text { Capillaroscopic abnormalities } \\
\text { Score }\end{array}$ & sE-selectin (mean \pm SD) $[\mathbf{n g} / \mathbf{m l}]$ & $\begin{array}{l}\text { Together } \\
(\mathbf{n}=\mathbf{1 0 6})\end{array}$ & $\begin{array}{l}\text { Controls } \\
(\mathbf{n}=\mathbf{4 0})\end{array}$ \\
\cline { 1 - 2 } 0 & $55.40 \pm 16.42^{1,3}$ & \multirow{2}{*}{$69.04 \pm 40.78^{1}$} & $32.81 \pm 10.14$ \\
\cline { 1 - 2 } & $55.05 \pm 18.35^{1,4}$ & & \\
\hline 3 & $65.65 \pm 18.35^{1}$ & & \\
\hline
\end{tabular}

${ }^{1}$ Statistical significance: $\mathrm{p}<0.001$ compared to healthy controls; ${ }^{2}$ Statistical significance: $\mathrm{p}<0.05$ compared to healthy controls;

${ }^{3}$ Statistical significance: $\mathrm{p}<0.05$ between diabetic groups ( 0 and 3$)$; ${ }^{4}$ Statistical significance: $\mathrm{p}<0.05$ between diabetic groups $(1$ and 3$)$

Table 4. Serum concentrations of IL18 in patients with type 1 diabetes according to the severity of microvascular changes in capillaroscopy and in healthy controls

\begin{tabular}{|l|c|c|c|}
\hline $\begin{array}{l}\text { Capillaroscopic abnormalities } \\
\text { Score }\end{array}$ & IL-18 mean \pm SD $[\mathbf{p g} / \mathbf{m l}]$ & $\begin{array}{c}\text { Together } \\
(\mathbf{n = 1 0 6})\end{array}$ & \multicolumn{1}{|c|}{$\begin{array}{c}\text { Controls } \\
(\mathbf{n}=\mathbf{4 0})\end{array}$} \\
\cline { 1 - 2 } 0 & $218.67 \pm 63.77^{2}$ & \multirow{2}{*}{$258.47 \pm 93.12^{1}$} & $217.41 \pm 59.81$ \\
\hline 1 & $212.79 \pm 74.56^{3}$ & & \\
\hline 3 & $259.12 \pm 73.37^{1}$ & & \\
\hline
\end{tabular}

${ }^{1}$ Statistical significance: $\mathrm{p}<0.05$ compared to healthy controls; ${ }^{2}$ Statistical significance: $\mathrm{p}<0001$ between diabetic groups $(0$ and 3$)$;

${ }^{3}$ Statistical significance: $\mathrm{p}<0.001$ between diabetic groups (1 and 3)

involvement and immunological parameters of disease activity in patients with connective tissue diseases [8].

There is growing understanding of the microvascular abnormalities in diabetes [17-19], but little is known about the relationship between capillaroscopic abnormalities, immunological parameters and the clinical features of type 1 diabetes. Furthermore, according to recent studies, chronic inflammation leads to the impairment of endothelial function and microvascular complications in the course of diabetes $[3,10]$. Our previous report showed a relation between the severity of capillaroscopic changes and metabolic control and the presence of persistent complications in patients with type 1 diabetes [18].

The present study evaluated the associations between nailfold capillaroscopic abnormalities, $\mathrm{sE}$-selectin and IL-18 serum levels and the clinical features of a cohort of 106 patients with type 1 diabetes. The intensity of capillaroscopic changes, expressed according to the established classification, ranged from 0 to $3[8,18]$.

The results of this study confirmed the findings of other authors who have reported a pattern of capillary changes expressed by decreased density, dilatations of venous limb, increased tortuosity of vascular loops and microaneurysms in the apical part of the loop [17].
In the present study, severe capillaroscopic changes were observed frequently in diabetic patients complicated by microangiopathy. The mean capillaroscopic score in diabetic patients with microangiopathy was significantly higher than in the group without complications $(p<0.001)$.

Therefore, it may be suggested that microvascular abnormalities in NC are an indicator to microangiopathy in diabetic patients, and useful in monitoring the severity of vascular changes. It has been suggested that increased pressure in the capillary vascular bed [17], nonenzymatic glycation of basal membrane proteins [20], endothelial dysfunction and angiogenic activity $[1,10]$ are implicated in the pathogenesis of microcirculation disturbances in diabetes.

Our present study demonstrated the relationship between the severity of capillaroscopic abnormalities and disease duration. This may confirm our previous findings [18]. In addition, other authors have reported the correlation between microvascular changes in capillaroscopy and the occurrence of retinopathy in 25 patients with type 1 diabetes [21]. Furthermore, in patients with type 2 diabetes, a relationship has been shown between the occurrence of hemostatic loops and disease duration, as well as the presence of persistent complications [20]. However, other authors did not find differences between 
the capillaroscopic features of type 1 diabetic patients and those of healthy volunteers [22].

The results of this study confirm that serum sE-selectin was significantly elevated in patients with capillaroscopic abnormalities in diabetic microangiopathy such as retinopathy, nephropathy or neuropathy, compared to a subgroup without microvascular changes. Moreover, we found significant differences in sE-selectin serum concentrations between diabetes patients with severe capillaroscopic changes and the subgroup without or with mild capillaroscopic changes $(p<0.05)$. Several studies have demonstrated elevated levels of sE-selectin in patients with diabetes [23]. Moreover, there was shown to be a positive correlation between the serum $\mathrm{sE-selectin} \mathrm{levels} \mathrm{and} \mathrm{the}$ presence of retinopathy, albuminuria and cardiovascular system diseases in 540 patients with type 1 diabetes in the EURODIAB Prospective Complication Study [24]. By contrast, according to other studies, serum levels of sE-selectin are not related to the presence of diabetic kidney disease in patients with type 1 diabetes [25].

In our study, we demonstrated significantly elevated levels of IL-18 in serum of type 1 diabetes patients, and in all subgroups with capillaroscopic abnormalities, compared to healthy controls. Moreover, the serum concentration of IL-18 was significantly higher in patients with severe microvascular changes in nailfold capillaroscopy ( score $=3$ ) compared to subgroups with normal capillaroscopic pattern or with mild abnormalities ( $\mathrm{p}<0.001)$. Katakami et al. observed increased levels and positive correlations between IL-18, sE-selectin and SICAM serum levels in 77 patients with type 1 diabetes. In the same study, a correlation between IL-18 concentration and metabolic control of the disease was found [23]. Moreover, elevated IL-18 serum levels were reported in patients with type 1 diabetes complicated by nephropathy [26]. Other authors have also demonstrated increased IL-18 serum levels in relation to the presence of persistent complications in the course of type 2 diabetes [12].

In the present study, we demonstrated significantly higher serum levels of sE-selectin and IL-18 in type 1 diabetic patients compared to healthy controls. Moreover, we found a relationship between elevated serum sE-selectin and IL-18 concentrations and the severity of microvascular capillaroscopy changes in patients with type 1 diabetes.

In conclusion, our findings suggest that abnormalities in nailfold capillaroscopy may reflect the severity of microvascular changes in the course of type 1 diabetes. Therefore, nailfold capillaroscopy may be a useful diagnostic and prognostic tool for the better evaluation and monitoring of microvascular complications in type 1 diabetic patients. Further investigations of the role of microvascular changes in the development of diabetic complications may be crucial for better diagnosis, monitoring and more effective strategies for the treatment of organ dysfunction in diabetic patients.

\section{References}

1. Shestakova MV, Jarek-Martynowa IR, Ivanishina NS et al. Role of endothelial dysfunction in the development of cardiorenal syndrome in patients with type 1 diabetes mellitus. Diabetes Res Clin Pract. 2005;68,(Suppl 1):S65-72.

2. Koch AE, Halloran MM, Haskell CJ, Shah MR, Polverini PJ. Angiogenesis mediated by soluble forms of E-selectin and vascular cell adhesion molecule-1. Nature. 1995;10:517-519.

3. Mohamed-Ali V, Armstrong L, Clarke D, Bolton CH, Pinkney JH. Evidence for the regulation of levels of plasma adhesion molecules by proinflammatory cytokines and their soluble receptors in type 1 diabetes. J Intern Med. 2001; 250:415-421.

4. Kuryliszyn-Moskal A, Klimiuk PA, Ciołkiewicz M, Sierakowski S. Clinical significance of selected endothelial activation markers in patients with systemic lupus erythematosus.J Rheumatol. 2008;35:1307-1313.

5. Modrzejewski W, Knapp M, Dobrzyn A, Musial WJ, Górski $\mathrm{J}$. Ceramides and adhesive molecules in stable ischaemic heart disease. Przegl Lek. 2008;65:131-134.

6. Cowley HC, Heney D, Gearing AJ, Hemingway I, Webster NR. Increased circulating adhesion molecule concentrations in patients with the systemic inflammatory response syndrome: a prospective cohort study. Crit Care Med. 1994;22: 651-657.

7. Franklin VL, Khan F, Kennedy G, Belch JJ, Greene SA. Intensive insulin therapy improves endothelial function and microvascular reactivity in young people with type 1 diabetes. Diabetologia. 2008;51:353-360.

8. Kuryliszyn-Moskal A, Ciołkiewicz M, Klimiuk PA, Sierakowski S. Clinical significance of nailfold capillaroscopy in systemic lupus erythematosus: correlation with endothelial cell activation markers and disease activity. Scand J Rheumatol. 2009;38:38-45.

9. Reddy P. Interleukin-18: recent advances. Curr Opin Hematol. 2004;11:405-410.

10. Skopiński P, Rogala E, Duda-Król B et al. Increased interleukin-18 content and angiogenic activity of sera from diabetic (type 2 ) patients with background retinopathy. J Diabetes Complications. 2005;19:335-338.

11. Zirlik A, Abdullah SM, Gerdes N et al. Interleukin-18, the metabolic syndrome, and subclinical atherosclerosis: results from the Dallas Heart Study. Arterioscler Thromb Vasc Biol. 2007;27:2043-2049.

12. Nakamura A, Shikata K, Hiramatsu M et al. Serum interleukin-18 levels are associated with nephropathy and atherosclerosis in Japanese patients with type 2 diabetes. Diabetes Care. 2005;28:2890-2895.

13. Mirończuk K, Okruszko A, Wawrusiewicz-Kurylonek N, Kretowski A, Kinalska I, Górska M. Interleukin 18 and sICAM1 serum levels in families with type 1 diabetes mellitus. Rocz Akad Med Bialymst. 2005;50:151-154.

14. Cutolo M, Grassi W, Matucci Cerinic M. Raynaud's phenomenon and the role of capillaroscopy. Arthritis Rheum. 2003;48:3023-3030. 
15. Górska A, Kowal-Bielecka O, Urban M et al. Impairment of microcirculation in juvenile idiopathic arthritis - studies by nailfold videocapillaroscopy and correlation with serum levels of sICAM and VEGF. Folia Histochem Cytobiol. 2008;46:443-447.

16. Ohtsuka T, Tamura T, Yamakage A, Yamazaki S. The predictive value of quantitative nailfold capillary microscopy in patients with undifferentiated connective tissue disease. $\mathrm{Br}$ J Dermatol. 1998;139:622-629.

17. Meyer MF, Pfohl M, Schatz H. Assessment of diabetic alterations of microcirculation by means of capillaroscopy and laser-Doppler anemometry. Med Klin. 2001;15:71-77.

18. Kuryliszyn-Moskal A, Zarzycki W, Dubicki A, Zonenberg A, Górska M. A study on microvascular abnormalities in capillaroscopy in patients with type 1 diabetes mellitus. Diabetol Dosw i Klin. 2006;6:1-6.

19. Pazos-Moura CC, Moura EG, Bouskela E, Torres-Filho IP, Breitenbach MM. Nailfold capillaroscopy in diabetes mellitus: morphological abnormalities and relationship with microangiopathy. Braz J Med Biol Res. 1987; 20:777-780.

20. Brownlee M. Biochemistry and molecular cell biology of diabetic complications. Nature. 2001;13:813-820.
21. Gasser P, Berger W. Nailfold videomicroscopy and local cold test in type I diabetics. Angiology. 1992;43:395-400.

22. Trapp RG, Soler NG, Spencer-Green G. Nailfold capillaroscopy in type I diabetics with vasculopathy and limited joint mobility. J Rheumatol. 1986;13:917-920.

23. Katakami N, Kaneto H, Matsuhisa $\mathrm{M}$ et al. Serum interleukin-18 levels are increased and closely associated with various soluble adhesion molecule levels in type 1 diabetic patients. Diabetes Care. 2007;30:159-161.

24. Soedamah-Muthu SS, Chaturvedi N, Schalkwijk CG, Stehouwer CD, Ebeling P, Fuller JH; The EURODIAB Prospective Complications Study group. Soluble vascular cell adhesion molecule-1 and soluble E-selectin are associated with microand macrovascular complications in Type 1 diabetic patients. J Diabetes Complications. 2006;20:188-195.

25. Clausen P, Jacobsen P, Rossing K, Jensen JS, Parving HH, Feldt-Rasmussen B. Plasma concentrations of VCAM-1 and ICAM-1 are elevated in patients with Type 1 diabetes mellitus with microalbuminuria and overt nephropathy. Diabet Med. 2000;17:644-649.

26. Mahmoud RA, el-Ezz SA, Hegazy AS. Increased serum levels of interleukin-18 in patients with diabetic nephropathy. Ital J Biochem. 2004;53:73-81.

Submitted: 24 February, 2010 Accepted after reviews: 31 January, 2011 